\title{
O SETOR DE MÓVEIS SUL-BRASILEIRO E AS BARREIRAS À ALCA
}

\author{
Gilson Martins*, João Carlos Garzel Leodoro da Silva**, Roberto Tuyoshy Hosokawa***, \\ Ricardo Berger** \\ *Eng. Florestal, M.Sc., Doutorando da Albert-Ludwigs-Universität Freiburg - martinsgilson@hotmail.com \\ **Eng. Florestal, Dr., Depto. de Economia Rural e Extensão, UFPR - garzel@ufpr.br - berger@floresta.ufpr.br \\ ***Eng. Florestal, Dr., Depto. de Ciências Florestais - hosokawa@pesquisador.cnpq.br \\ Recebido para publicação: 03/05/2004 - Aceito para publicação: 12/06/2007
}

\begin{abstract}
Resumo
Este estudo analisa a percepção dos empresários sul-brasileiros do setor de móveis sobre as barreiras para a atuação das empresas na Área de Livre Comércio das Américas (Alca). Para tanto, enviou-se um questionário estruturado à alta administração de empresas dos estados do Paraná, Santa Catarina e Rio Grande do Sul. A metodologia de análise estatística dos dados utilizada foi a Análise de Correspondências Simples em conjunto com a Análise de Cluster. Concluiu-se principalmente que os empresários atribuem mais importância às barreiras externas do que às internas às empresas.

Palavras-chave: Análise de correspondência; barreiras nas exportações; exportação de móveis.
\end{abstract}

\section{Abstract}

The south-Brazilian furniture industry and the Afta barriers. This study case presents the analysis of the Perception of the south-Brazilian furniture industry entrepreneurs on the barriers of the American Free Trade Area (Afta). A structured survey was sent to the furniture firms located in the SouthBrazilian States: Paraná, Santa Catarina and Rio Grande do Sul. The Simple Correspondence Analysis and the Cluster Analysis were the statistical methods used for collected data processing. The results point out that for the furniture entrepreneurs the firm external barriers are more important than the firm internal barriers.

Keywords: Correspondence analysis; export barriers; furniture exports.

\section{INTRODUÇÃO}

A Alca é um projeto de integração comercial que, se consolidado, englobará 34 países das três Américas, somando um PIB de US\$ 11,5 trilhões e uma população de 800 milhões de habitantes. Um projeto de tal envergadura pode ter efeitos sociais e econômicos de grande magnitude. Mas a sua consolidação depende, em um primeiro momento, da percepção dos líderes negociadores sobre a favorabilidade da Alca. As simulações dos efeitos do acordo ajudam nesse processo decisório. No entanto, este estudo assume que a percepção dos atores econômicos sobre o ambiente de negócios da Alca também possui um importante papel na tomada de decisões.

Segundo Carvalho; Parente (1999), a Alca traria para o Brasil um aumento muito maior do volume de importações do que de exportações. A simulação de Gourgel et al. (2002) contribui para a confirmação dessa tese. No entanto, para Gourgel et al, no caso dos produtos florestais, haveria aumentos de $0,23 \%$ na produção e de $3,3 \%$ nas exportações, mas as importações aumentariam em $25,7 \%$. Haveria um ganho de US\$ 470 mil na balança comercial de produtos florestais.

Domingues; Haddad (2003) simularam os impactos da Alca em uma perspectiva regional. Segundo os autores, a Alca possuirá efeitos regionais diferenciados no Brasil, mas de modo geral positivos para o crescimento do PIB e para a geração de superávit comercial no longo prazo. O trabalho demonstra que os efeitos para o setor de madeira mobiliário seriam positivos, mas modestos quando comparados com outros setores, como o de calçados ou agropecuária.

Em Brasil/MDIC (2003) avaliam-se os aspectos relevantes e prioritários para a competitividade de 20 setores da economia brasileira frente à Alca, dentre os quais a cadeia produtiva de madeira e móveis. Assim, esse setor possui prioridades de políticas principalmente relacionadas à promoção comercial. A reestruturação da política industrial e a atração de capital estrangeiro são aspectos de muita relevância para o sucesso do setor. 
Conforme assumido anteriormente, para um bom posicionamento estratégico na Alca, além de simulações dos efeitos econômicos, é importante se considerar a percepção dos atores econômicos sobre o acordo. Desse modo, neste estudo os esforços são concentrados na análise do setor de móveis brasileiro. O objetivo é, portanto, trazer a Alca à percepção dos empresários do setor de móveis sul-brasileiro. Abordam-se, neste estudo, percepções sobre aspectos gerais e sobre as barreiras para exportação na Alca.

\section{Barreiras para as exportações}

A revisão apresentada a seguir está organizada de forma a abranger primeiramente as barreiras relativas ao ambiente de negócios internacional, incluindo aspectos institucionais, políticos, competitivos e culturais. Na seqüência, apresentam-se as barreiras relativas ao ambiente de negócios nacional, contemplando, sobretudo, aspectos políticos e econômicos relacionados às exportações. Por último, são apresentadas as barreiras relativas ao ambiente interno das empresas.

$\mathrm{Na}$ integração econômica de livre comércio, o principal objetivo é eliminar as barreiras tarifárias existentes entre os países. O Brasil adota o sistema de tarifa externa comum (TEC) do Mercosul. Para os produtos moveleiros ${ }^{1}$, essa tarifa é atualmente de 19,5\% (Ad valorem), sendo que entre os países do Mercosul essa tarifa é nula. Esse valor é superado pela média tarifária adotada pelo México, que é de 24,3\% para 16 produtos de 8 dígitos da Seção 9403. Já as tarifas aplicadas pelos EUA (abrangendo 23 produtos de 8 dígitos) são nulas. As tarifas aplicadas pelo Canadá são em média de $5 \%$, com acordos preferenciais de tarifas médias de 3,0\% para o Brasil. A União Européia aplica uma tarifa média de $0,8 \%$ (Unicamp-IE-NEIT, 2002).

No entanto, as barreiras tarifárias não são o único tipo de barreira que as empresas enfrentam no mercado externo. Barbosa ${ }^{2}$, citado por Unicamp-IE-NEIT, destaca, além desse, outros dois tipos de barreiras: barreiras não-tarifárias (restrições quantitativas, licenciamento e importações, procedimentos alfandegários, medidas antidumping e compensatórios) e barreiras técnicas (normas e regulamentos técnicos, regulamentos sanitários, fitossanitários e de saúde animal).

Kume et al. (2001) e Silva; Rocha (2001) estudaram a percepção dos empresários brasileiros exportando para o Mercosul. Nesses estudos, os entrevistados atribuem de modo geral uma importância moderada ou pouca importância para as barreiras não-tarifárias. Já Martins et al. (2004) analisaram os problemas para exportar enfrentados pelas empresas de móveis brasileiras. No que diz respeito às barreiras técnicas, as dificuldades de conformidade aos padrões externos são raramente citados pelos empresários como um entrave para a expansão das exportações. Por outro lado, na análise de Kume et al. (2001), observa-se que as barreiras técnicas são freqüentemente tidas como importantes para setores como o de abate de animais, de calçados e de produtos alimentícios.

Silva; Rocha (2001) analisaram os requerimentos de qualidade no Mercosul. Esse aspecto é apontado como de importância moderada pelos empresários exportando para esse mercado. As exigências ambientais dos países importadores, analisadas no estudo de Silva (1996), também é um aspecto inerente à qualidade dos produtos de crescente interesse nos mercados internacionais.

O ambiente competitivo internacional, nos estudos de Kume et al. (2001) e de Silva; Rocha (2001), é considerado a segunda mais importante barreira pelos empresários que exportam para o Mercosul. Em Leonidou (1995), essa foi a barreira mais citada. Em contraste, no estudo de Bauerschmidt (1985) sobre a indústria de papéis norte-americana, a competição internacional não assume elevados graus de importância.

$\mathrm{Na}$ literatura, encontra-se também referência à imagem do Brasil e do produto brasileiro no exterior (ROCHA; CHRISTENSEN, 1994; SILVA, 1996; SILVA; ROCHA, 2001). Segundo o estudo de Silva e Rocha, a falta de aceitação dos produtos brasileiros não é vista como uma forte barreira para as exportações. Esse, no entanto, é um assunto de corrente reincidência nas iniciativas de promoção comercial brasileiras, como a Apex e a Promóvel (APEX, 2002; ABIMÓVEL, 2003).

De acordo com Silva; Rocha (2001), os exportadores brasileiros consideram os altos custos de transporte e seguro de elevada importância para as exportações para o Mercosul. Martins et al. (2004) assumem que os custos de frete internacional, assim como a variável operacional "transporte internacional", tem elevado grau de importância para a indústria de móveis. É interessante notar que no estudo de Leonidou não se encontrou diferença entre a percepção de exportadores e não importadores

\footnotetext{
${ }^{1}$ Aqui é considerada a seção 9043 do Sistema Harmonizado, que engloba os móveis de madeira, de metal, de plástico, de outros materiais e partes de móveis.

${ }^{2}$ BARBOSA, R.A. Barreiras Comerciais dos Estados Unidos. Washington, D.C: Embaixada do Brasil. 2001.
} 
para a variável transporte problemático/altos custos de transporte, sendo assinalada com grande freqüência como uma barreira por ambos os tipos de empresas.

Os riscos de exportação incluem não apenas aqueles existentes no mercado externo e que as empresas enfrentam igualmente nos mercados domésticos, mas também riscos existentes no mercado externo que não são enfrentados nos mercados domésticos (KORTH, 1991). Em Bauerschmidt e Gillespie (1985), os exportadores do setor de papel norte-americanos consideram os riscos de vendas no exterior como tendo uma importância moderada. A percepção de risco associa-se também à situação política nos mercados. Nesse sentido, em Silva; Rocha (2001) os entrevistados brasileiros atribuem um grau de importância moderado para a instabilidade política do Mercosul. Ainda, Simpson; Kujawa ${ }^{3}$, citados por Christensen; Rocha; Gertner (1987), demonstram que os exportadores possuem menor aversão ao risco do que os não-exportadores.

$\mathrm{Na}$ literatura, observam-se também estudos relacionados às barreiras referentes ao ambiente de negócios nacional às empresas. Karakaya; Harcar (1999) identificaram as informações inadequadas sobre os recursos financeiros como uma das mais importantes barreiras para as exportações. A variável custo do capital para financiar a produção é considerada no estudo de Silva (1996) e Martins et al. (2004). No estudo de Martins et al. (2004), os empresários percebem com alta freqüência a dificuldade de acesso ao financiamento às exportações como uma importante barreira. Segundo a análise dos autores, as empresas de móveis usam preponderantemente os mecanismos comerciais de financiamento em detrimento de mecanismos oficiais, como os do BNDS e do Banco do Brasil.

Em Martins et al. (2004), os custos portuários são considerados uma importante barreira apenas para uma pequena parcela dos empresários do setor de móveis. O conjunto dos outros setores da economia brasileira, em contraste, atribui um elevado grau de importância para esse tipo de custo. Já em Silva e Rocha (2001), a variável custos de seguro e transporte assume elevado grau de importância.

Em Silva; Rocha (2001), a variável incentivos para exportação é tida como a mais importante barreira para as firmas brasileiras exportando para o Mercosul. Em contraste, no estudo de Kume et al. (2001) a política doméstica brasileira é assinalada por poucos empresários.

Em Silva; Rocha (2001), os empresários atribuem um elevado grau de importância para a política do governo com relação ao câmbio para os trâmites burocráticos brasileiros. É interessante notar que em Bauerschmidt os empresários do setor de papel e celulose norte-americano também atribuem elevada importância para a política cambial.

Um último grupo de barreiras diz respeito às barreiras internas às empresas. Uma primeira variável é o conflito com importadores. Segundo Silva (1996), essa barreira assume pouca importância, no caso dos empresários do setor de papel e celulose brasileiros.

Alguns autores estudaram o acesso aos distribuidores e atacadistas em mercados estrangeiros e as "dificuldades em escolher representantes no mercado externo". Em Silva; Rocha (2001), ambas as barreiras são de pouca importância para os empresários exportando para o Mercosul. Em Kume et al. (2001), percebe-se que a variável canal de distribuição é freqüentemente assinalada como um obstáculo às exportações para o Mercosul, mas se atribui a ela apenas uma importância moderada com relação às outras barreiras. No estudo de Karakaya e Harcar (1999), as firmas não-exportadoras de países em desenvolvimento atribuem alta importância para a barreira inadequadas informações de mercado.

Segundo Korth (1985), "uma fonte de medo" de negócios internacionais relaciona-se às diferenças existentes entre o ambiente doméstico e ambientes internacionais. Nesse contexto, a literatura cita com freqüência as diferenças de língua e cultura. Vale aqui ressaltar os resultados de Silva (1996) e Silva; Rocha (2001), nos quais os entrevistados atribuem pouquíssima importância para essa barreira.

Kaynak (1992) relaciona a percepção de elevados custos de produção como uma barreira que pode afetar a performance das empresas nas exportações. Por outro lado, a qualificação da mão-de-obra é uma variável considerada na literatura. No entanto, em Silva; Rocha (2001) percebe-se que os empresários não consideram as dificuldades na contratação de pessoas qualificadas para as atividades de exportação como uma barreira de grande peso para as empresas.

Em Silva; Rocha (2001), observa-se que a falta de técnicas administrativas para exportações assume a $17^{\mathrm{a}}$ posição em um ranking de 26 barreiras. Para Axinn (1988), a complexidade de exportação é o grau em que a exportação é percebida como sendo difícil para ser implementada ou realizada. Dentre os fatores mais freqüentemente citados em Silva; Rocha (2001), ressaltam-se a burocracia e o financiamento

\footnotetext{
${ }^{3}$ Simpson, C.L.; Kujawa, D. The export decision process: an empirical enquiry. Journal of International Business Studies, Columbia, SC, p-107-117, Spring, 1974.
} 
às exportações. Assim, a complexibilidade das técnicas administrativas necessárias para exportar assume a $25^{\mathrm{a}}$ posição na lista de barreiras.

Enfim, a necessidade de servir o mercado interno é citada na literatura como uma barreira para as exportações (BAUERSCHMIDT, 1985; KORTH, 1991; ROCHA; CHRISTENSEN, 1994; LEONIDOU, 1995; CARRIER, 1996). Para Korth, a percepção de que existem oportunidades suficientes no mercado interno se relaciona com a variável ambição limitada do empresário. Nesse contexto, uma outra barreira também freqüentemente estudada é a falta de capacidade para aumentar a oferta no mercado externo (SILVA, 1996; LEONIDOU, 1995; CARRIER, 1996; INFANTE; IDROGO, 1998).

Na revisão acima, foram abrangidos os aspectos de maior relevância relacionados às discussões desta pesquisa, não se ambicionando uma abrangência total do assunto barreiras. No Quadro 2, é apresentada uma lista com as principais referências relacionadas às barreiras examinadas nesta pesquisa. Essa lista baseia-se sobretudo em Silva; Rocha (2001) e Martins (2003).

\section{METODOLOGIA}

Os dados primários desta pesquisa foram obtidos por meio de um questionário estruturado e não disfarçado direcionado à alta administração das empresas de móveis dos principais pólos moveleiros da região Sul do Brasil. As listagens das empresas entrevistadas foram obtidas junto aos sindicatos e associações das indústrias de móveis de Arapongas (SIMA), São Bento do Sul (SINDUSMOBIL) e Rio Grande do Sul (MOVERGS).

Assim, foram enviados questionários para empresários dos pólos moveleiros do país de Arapongas (PR), São Bento do Sul (SC) e Bento Gonçalves (RS). Um formulário com as questões foi enviado, juntamente com uma carta de apresentação do projeto, por correio eletrônico (formato Word) ou por fax, conforme a preferência do entrevistado, após contato telefônico em que se procurou explicitar os objetivos da pesquisa. O entrevistado tinha o prazo de 15 dias para retornar o formulário de respostas.

As barreiras incluídas no questionário foram escolhidas através da análise da literatura de marketing internacional. No entanto, as questões desta pesquisa foram adaptadas, de maneira que o entrevistado deveria considerar suas respostas para um ambiente de funcionamento da Alca. Além de questões sobre as barreiras, foram incluídas também no questionários questões relativas à percepção geral sobre a Alca, baseadas sobretudo em AT Kearney (2001).

A percepção dos empresários sobre as barreiras foi quantificada através da escala de Likert. Pediu-se aos entrevistados para atribuir notas de 1 a 5 às questões apresentadas, conforme os seguintes graus de importância: 1 = Não importante (NI); 2 = Pouco Importante (PI); 3 = Importância Moderada (IM); 4 = Importante (I); 5 = Muito importante (MI). Como as variáveis em questão são categóricas, optou-se para a sua análise pelo uso da técnica da Análise Fatorial de Correspondências (AFC) ${ }^{4}$, conforme indicado por Hoffman; Franke (1986). Esse tipo de análise está inserido na família das técnicas de mapas perceptuais/intuitivos. De maneira geral, esse mapa apresenta percepções opostas nos opostos dos eixos X e Y. Por exemplo: importante e não importante; doce e azedo.

Tanto Hoffman; Franke (1986) quanto Cunha (2000) assinalam que, após a realização da AFC, pode ser necessária a realização de outras análises estatísticas para auxiliar nas interpretações dos dados. Assim, devido ao grande número de variáveis e por consequiência a dificuldade de analisá-las graficamente, optou-se neste trabalho por realizar ainda uma análise de agrupamento (Cluster analysis). Conforme Johnson; Wichern (1998), na análise o agrupamento é feito na base de medidas de similaridades ou distâncias. O objetivo básico desse tipo de análise é descobrir agrupamentos naturais entre variáveis. Assim sendo, adotaram-se, ordenadamente, os seguintes passos para a análise das barreiras: a) Análise de correspondências; b) Análise de cluster com as coordenadas da AFC; e c) Montagem de um quadro contendo as variáveis percepcionais e atributo de importância mais característico. Quanto às perguntas relacionadas à percepção geral sobre a Alca, procedeu-se uma análise gráfica dos resultados. A análise desses aspectos forneceu suporte para as discussões relacionadas com as barreiras.

\footnotetext{
${ }^{4}$ Para detalhes sobre a teoria e aplicações da AFC, sugere-se uma consulta a Hoffman (1986), Kaciak e Louviere (1990), Hair et al. (1995), Valentin (2000), Bendixen (2003).
} 


\section{PERCEPÇÃO GERAL SOBRE A ALCA}

Os resultados apresentados na figura 1 mostram que os empresários não são claramente favoráveis à Alca. Esse fato é denotado pelo percentual de respostas "sim, com restrições". Verifica-se que os empresários de pequeno envolvimento nas exportações possuem um posicionamento semelhante aos de maior envolvimento. Somando-se as duas classes de entrevistados, verifica-se que $28 \%$ são favoráveis à Alca, enquanto que um percentual de $65 \%$ são "favoráveis com restrições".

Poucos empresários afirmam estar fazendo algum tipo de planejamento em função da Alca. Distingue-se, na figura 2, que apenas $14 \%$ dos entrevistados dizem estar fazendo alguma mudança de plano em função da Alca. Dos demais entrevistados, $27 \%$ dizem estar considerando, mas sem mudanças de planos em função dela, e $60 \%$ afirmam não estar considerando.

Dos empresários do setor de móveis deste estudo, $62 \%$ dizem não estar envolvidos em grupos de pressão relacionados à Alca (Figura 3). Dos demais empresários desta pesquisa, 35\% dizem que a sua forma de envolvimento é via associações setoriais.

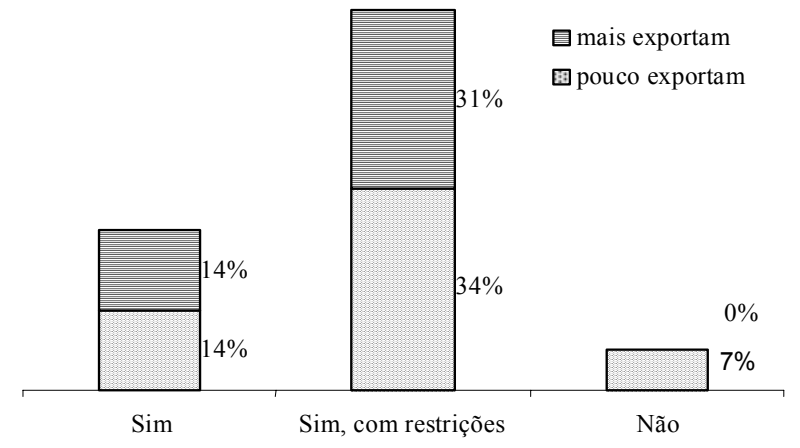

Figura 1. Porcentagem dos entrevistados favoráveis e não-favoráveis à Alca. (No grupo dos que menos exportam, consideraram-se 16 empresas que apresentaram um percentual menor do que $25 \%$ nas exportações em 2001, sendo que 7 não exportaram nada).

Figure 1. The agreement of interviewees regarding Afta.

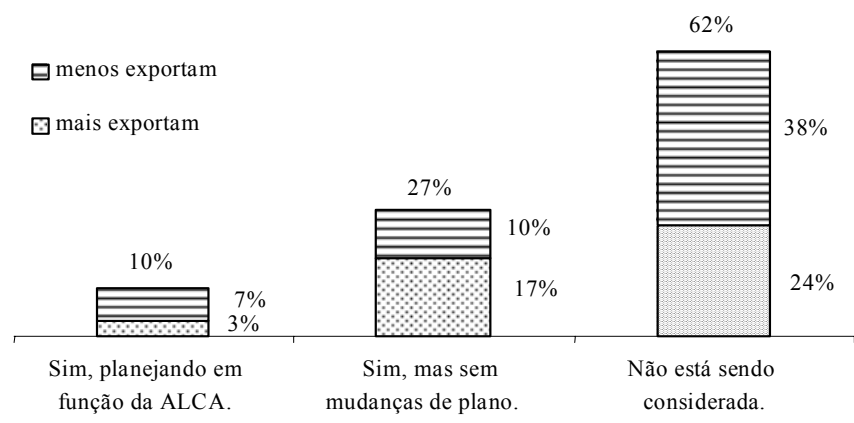

Figura 2. A Alca no planejamento das empresas.

Figure 2. American Free Trade Area (Afta) in the firms plans.

Ao serem questionados sobre a capacitação das suas empresas, a maioria dos empresários respondeu que estão preparados para atuar na Alca. 57\% dos empresários julgam estar preparados para a Alca, enquanto $3 \%$ dizem estar "totalmente" preparados. Um percentual de $17 \%$ admite não estar preparado (Figura 4).

Perguntou-se também aos empresários se eles acham que o setor como um todo está suficientemente envolvido nas negociações da Alca. Verifica-se que a grande maioria dos entrevistados acredita que falta envolvimento do setor (Figura 5). 


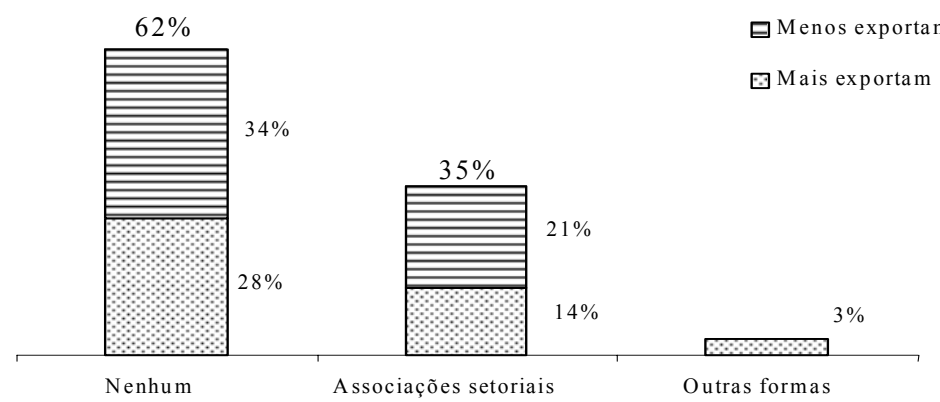

Figura 3. Grau de envolvimento em grupos de pressão para negociações da Alca.

Figure 3. Degree of involvement in pressure groups for the Afta negotiations.

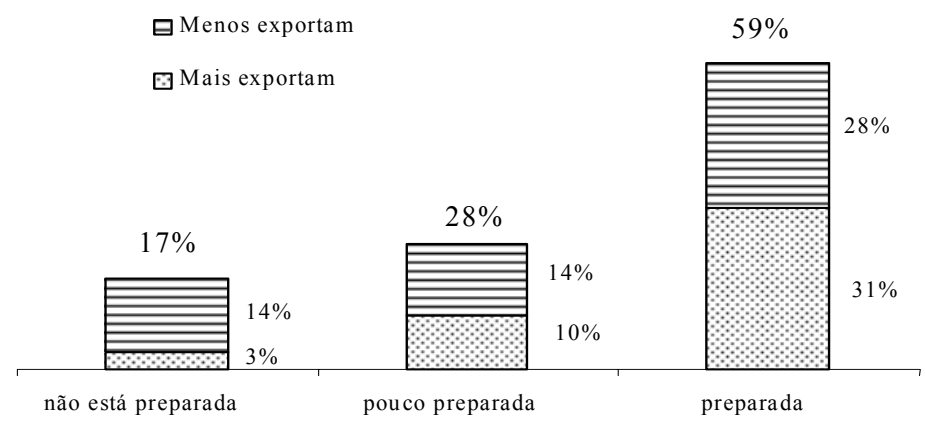

Figura 4. Percepção sobre o grau de preparo da empresa para enfrentar a Alca.

Figure 4. Perceptions on the preparation of the firms to compete in the Afta.

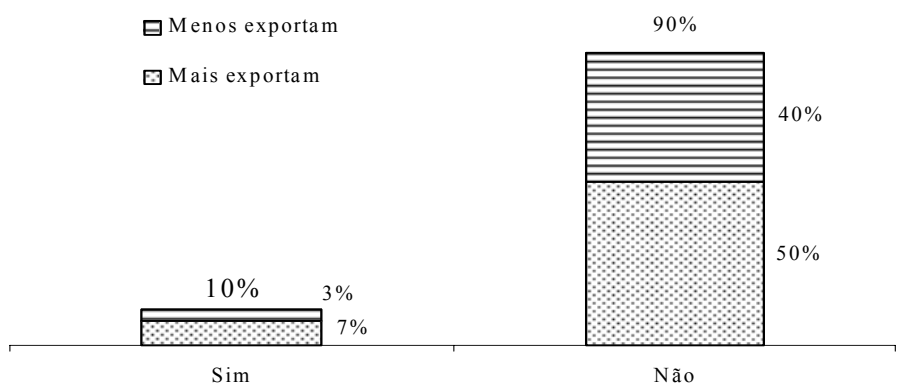

Figura 5. O setor de móveis como um todo está suficientemente envolvido nas negociações da Alca?

Figure 5. Is the furniture sector enough involved in the Afta negotiations?

As questões anteriores relativas às atitudes gerais dos empresários têm importantes implicações para este estudo. Em primeiro lugar, observou-se que os empresários são favoráveis a um conceito geral da Alca, porém percebem tal processo com restrições, pois essa foi a resposta de $65 \%$ dos entrevistados (Figura 1). Uma segunda observação refere-se a uma inconsistência observada em algumas respostas dos empresários. Quando são questionados sobre o grau de preparo para enfrentar a Alca (Figura 4), a maioria dos entrevistados (64\%) responde que está preparada. Essa resposta não condiz com respostas de outras questões.

Quando são questionados sobre se a Alca está sendo considerada no planejamento das empresas (Figura 2), a maioria dos empresários (62\%) diz que a Alca não está sendo considerada. Em seguida, quando respondem a questão sobre a participação em grupos de pressão (Figura 3), $62 \%$ dos empresários respondem que não estão envolvidos nesse tipo de grupo, enquanto $35 \%$ dizem que estão envolvidos via associação setorial. Como se pode observar, o grau de envolvimento ainda é pequeno, ou, seja, o setor 
não está suficientemente envolvido nas negociações da Alca. Assim, a resposta de que as empresas estão preparadas parece incongruente com o fato de elas não estarem considerando a participação no planejamento.

Esses resultados têm importantes implicações para a análise dos resultados das barreiras percebidas para a Alca. Se, de modo geral, os empresários ainda não consideram ou planejam em função da Alca, as respostas para as perguntas das barreiras não foram pensadas para a Alca, mas em função da atividade exportadora ou do ambiente econômico atual. Assim, é mais seguro afirmar que as análises conseguintes referem-se mais à percepção dos empresários sobre as exportações ou ambiente econômico no futuro próximo e não necessariamente na Alca.

\section{PERCEPÇÃO DAS BARREIRAS ÀS EXPORTAÇÕES}

Na tabela 1 são apresentados os resultados da AFC com os dados da pesquisa. Na tabela 2 são apresentadas as principais estatísticas relativas a essa análise. Observa-se que duas dimensões respondem, juntas, por $82,7 \%$ da inércia total.

Tabela 1. Principais estatísticas da AFC para as barreiras (2 eixos selecionados).

Table 1. Statistic indexes for the AFC analysis of barriers (2 selected dimentions).

\begin{tabular}{|c|c|c|c|c|c|c|c|c|c|}
\hline & $\begin{array}{l}\text { Coord. } \\
\text { Dim.1 }\end{array}$ & $\begin{array}{c}\text { Coord. } \\
\text { Dim.2 }\end{array}$ & Mass & Quality & $\begin{array}{c}\text { Relative } \\
\text { Inertia }\end{array}$ & $\begin{array}{c}\text { Inertia } \\
\text { Dim.1 }\end{array}$ & $\begin{array}{c}\text { Cosine }^{2} \\
\text { Dim.1 }\end{array}$ & $\begin{array}{c}\text { Inertia } \\
\text { Dim.2 }\end{array}$ & $\begin{array}{c}\text { Cosine }^{2} \\
\text { Dim.2 }\end{array}$ \\
\hline AGTI & $-0,436$ & 0,097 & 0,039 & 0,739 & 0,025 & 0,027 & 0,704 & 0,005 & 0,035 \\
\hline PGRC & $-0,776$ & $-0,577$ & 0,039 & 0,970 & 0,089 & 0,087 & 0,625 & 0,169 & 0,345 \\
\hline CCFP & $-0,308$ & 0,020 & 0,039 & 0,888 & 0,010 & 0,014 & 0,885 & 0,000 & 0,004 \\
\hline CCFP & $-0,169$ & 0,198 & 0,039 & 0,787 & 0,008 & 0,004 & 0,330 & 0,020 & 0,456 \\
\hline FCAOME & 0,730 & $-0,036$ & 0,039 & 0,971 & 0,051 & 0,077 & 0,969 & 0,001 & 0,002 \\
\hline DLC & 0,807 & $-0,214$ & 0,038 & 0,624 & 0,100 & 0,091 & 0,583 & 0,022 & 0,041 \\
\hline CFLMPIA & 0,673 & $-0,237$ & 0,039 & 0,833 & 0,057 & 0,065 & 0,741 & 0,029 & 0,092 \\
\hline CEOP & $-0,088$ & 0,588 & 0,039 & 0,957 & 0,034 & 0,001 & 0,021 & 0,175 & 0,936 \\
\hline EMPME & 0,623 & $-0,178$ & 0,038 & 0,673 & 0,056 & 0,054 & 0,622 & 0,016 & 0,051 \\
\hline DCME & 0,344 & 0,123 & 0,039 & 0,945 & 0,013 & 0,017 & 0,838 & 0,008 & 0,107 \\
\hline ACFME & $-0,105$ & $-0,088$ & 0,038 & 0,104 & 0,016 & 0,002 & 0,061 & 0,004 & 0,043 \\
\hline $\mathrm{CP}$ & $-0,352$ & 0,146 & 0,038 & 0,758 & 0,017 & 0,017 & 0,647 & 0,010 & 0,111 \\
\hline IBE & $-0,519$ & 0,096 & 0,039 & 0,703 & 0,037 & 0,039 & 0,679 & 0,005 & 0,023 \\
\hline IPBE & $-0,749$ & $-0,363$ & 0,039 & 0,997 & 0,064 & 0,081 & 0,808 & 0,067 & 0,190 \\
\hline BNTPI & $-0,221$ & 0,136 & 0,039 & 0,609 & 0,010 & 0,007 & 0,441 & 0,009 & 0,168 \\
\hline CI & 0,373 & $-0,165$ & 0,039 & 0,753 & 0,020 & 0,020 & 0,630 & 0,014 & 0,124 \\
\hline EAPI & $-0,063$ & 0,298 & 0,039 & 0,760 & 0,011 & 0,001 & 0,033 & 0,045 & 0,728 \\
\hline IBAE & $-0,851$ & $-0,599$ & 0,039 & 0,999 & 0,101 & 0,104 & 0,668 & 0,182 & 0,331 \\
\hline TBB & $-0,405$ & 0,312 & 0,039 & 0,709 & 0,034 & 0,024 & 0,445 & 0,049 & 0,264 \\
\hline RME & 0,378 & 0,202 & 0,039 & 0,963 & 0,018 & 0,021 & 0,749 & 0,021 & 0,213 \\
\hline ВТР & 0,952 & $-0,363$ & 0,038 & 0,960 & 0,097 & 0,126 & 0,838 & 0,065 & 0,122 \\
\hline QMO & 0,101 & 0,212 & 0,038 & 0,470 & 0,011 & 0,001 & 0,086 & 0,022 & 0,384 \\
\hline MTA & 0,210 & 0,291 & 0,038 & 0,747 & 0,016 & 0,006 & 0,256 & 0,042 & 0,491 \\
\hline CQ & $-0,427$ & 0,149 & 0,038 & 0,897 & 0,020 & 0,025 & 0,800 & 0,011 & 0,097 \\
\hline NSMI & 0,716 & $-0,124$ & 0,038 & 0,693 & 0,068 & 0,071 & 0,672 & 0,008 & 0,020 \\
\hline $\mathrm{ACP}$ & $-0,365$ & 0,073 & 0,038 & 0,821 & 0,015 & 0,019 & 0,789 & 0,003 & 0,032 \\
\hline
\end{tabular}

FONTE: Elaborado pelos autores com dados da pesquisa.

Nota: As barreiras correspondentes às abreviações acima são mostradas na tabela 2 abaixo.

Para uma melhor visualização dos resultados, procedeu-se a uma análise de cluster (Figura 6). Assim, foram consideradas as coordenadas de duas dimensões das barreiras e dos atributos da AFC da tabela 1. Com isso, foram colocados no mesmo grupo as barreiras e os seus atributos de importância mais característicos. Distinguem-se, portanto, dois grandes grupos de barreiras, que são ainda passíveis de subdivisão. Na tabela 3 são apresentados os subgrupos resultantes da análise. 
Tabela 2. Autovalores e porcentagem da inércia explicada para a AFC das barreiras.

Table 2. Eigenvalues and percentage of explained inertia of AFC analysis of the barriers.

\begin{tabular}{cccccc}
\hline \multicolumn{2}{l}{ Total Inertia $=, 42003 \mathrm{Chi}^{2}=323,42 \mathrm{df}=100 \mathrm{p}=0,0000$} & & & \\
& $\begin{array}{c}\text { Singular } \\
\text { Values }\end{array}$ & $\begin{array}{c}\text { Eigen- } \\
\text { Values }\end{array}$ & $\begin{array}{c}\text { Perc. of } \\
\text { Inertia }\end{array}$ & $\begin{array}{c}\text { Cumulative } \\
\text { Percent }\end{array}$ & $\begin{array}{c}\text { Chi } \\
\text { Squares }\end{array}$ \\
\hline 1 & 0,5203 & 0,2707 & 64,4 & 64,4 & 208,4 \\
2 & 0,2771 & 0,0768 & 18,3 & 82,7 & 59,1 \\
3 & 0,2104 & 0,0443 & 10,5 & 93,3 & 34,1 \\
4 & 0,1680 & 0,0282 & 6,7 & 100,0 & 21,7 \\
\hline
\end{tabular}

Fonte: Autor.

Tabela 3. Barreiras e os atributos de importância 5 .

Table 3. Barriers and the atributes of importance.

\begin{tabular}{|c|c|c|c|}
\hline Barreiras & & Importância & \multirow{16}{*}{ 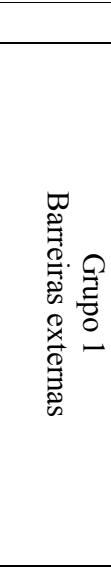 } \\
\hline IPBE & Imagem do produto moveleiro do Brasil no exterior & \multirow{3}{*}{$\begin{array}{c}\text { Muito } \\
\text { importante } \\
\text { (MI) }\end{array}$} & \\
\hline IBAE & Impostos brasileiros que afetam as exportações & & \\
\hline PGRC & Política do governo com relação ao câmbio & & \\
\hline EAPI & Exigências ambientais de outros países & \multirow{12}{*}{ Importante (I) } & \\
\hline CEOP & Concorrência de exportadores de outros países & & \\
\hline ACFME & Altos custos de frete para o mercado externo & & \\
\hline BNTPI & Barreiras não-tarifárias nos países importadores & & \\
\hline CCFP & Custo do capital para financiar a produção & & \\
\hline TBB & Trâmites burocráticos brasileiros & & \\
\hline CCFE & Custo do capital para financiar as exportações & & \\
\hline IBE & Imagem do Brasil no exterior & & \\
\hline $\mathrm{ACP}$ & Altos custos de produção & & \\
\hline $\mathrm{CP}$ & Custos portuários & & \\
\hline $\mathrm{CQ}$ & Controle de qualidade & & \\
\hline AGTI & Assistência governamental e taxas de incentivo & & \\
\hline CI & Conflitos com importadores & & \\
\hline MTA & Melhores técnicas administrativas & & \\
\hline QMO & Qualificação da mão-de-obra & Importancia & E. \\
\hline RME & Riscos no mercado externo & & $\pi$ \\
\hline DCME & Dificuldades de contatos no mercado externo & & $\Xi \cdot \Xi \cong$ \\
\hline BTP & Barreiras técnicas na produção & & 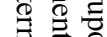 \\
\hline DLC & Diferenças de língua e cultura & Não importante & 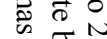 \\
\hline EMPME & Exigências de modificação de produto no mercado externo & $(\mathrm{NI})$ & 唚 \\
\hline CFLMPIA & Concorrência de firmas locais no mercado da Alca & Pouco & Q. \\
\hline NSMI & Necessidade de servir ao mercado interno. & importante (PI) & 宽 \\
\hline FCAOME & Falta de capacidade para aumentar a oferta no mercado ext & & \\
\hline
\end{tabular}

NOTA: A análise de variância multivariada (MANOVA) indica que há uma diferença estatística significativa entre os grupos. Ainda, a comparação entre médias, considerando um eixo de cada vez, demonstra que as médias dos grupos são todas diferentes, em níveis probabilísticos superiores a $99 \%$.

Observa-se, na figura 6, que os empresários julgam as barreiras relativas ao ambiente de negócios nacional e internacional mais importantes do que as barreiras internas às empresas. Esse fato foi observado em outras pesquisas em países desenvolvidos e países em desenvolvimento (BAUERSCHMIDT, 1985; LEONIDOU, 1995; SILVA; ROCHA, 2001). Silva; Rocha (2001) explicam esse fenômeno com a "teoria da atribuição", segundo a qual os indivíduos tendem a explicar resultados negativos de suas ações com fatores do ambiente externo, mas se os resultados são positivos, eles atribuem isso às suas próprias ações (OLIVER, $1997^{6}$, citado por SILVA; ROCHA, 2001).

\footnotetext{
${ }^{5}$ Considerando a ALCA em funcionamento, qual o grau de importância das BARREIRAS listadas abaixo para a sua empresa?

${ }^{6}$ Oliver, R. L., 1997. Satisfaction: a behavioural Perspective on the Consumer, McGraw-Hill, Boston, MA.
} 


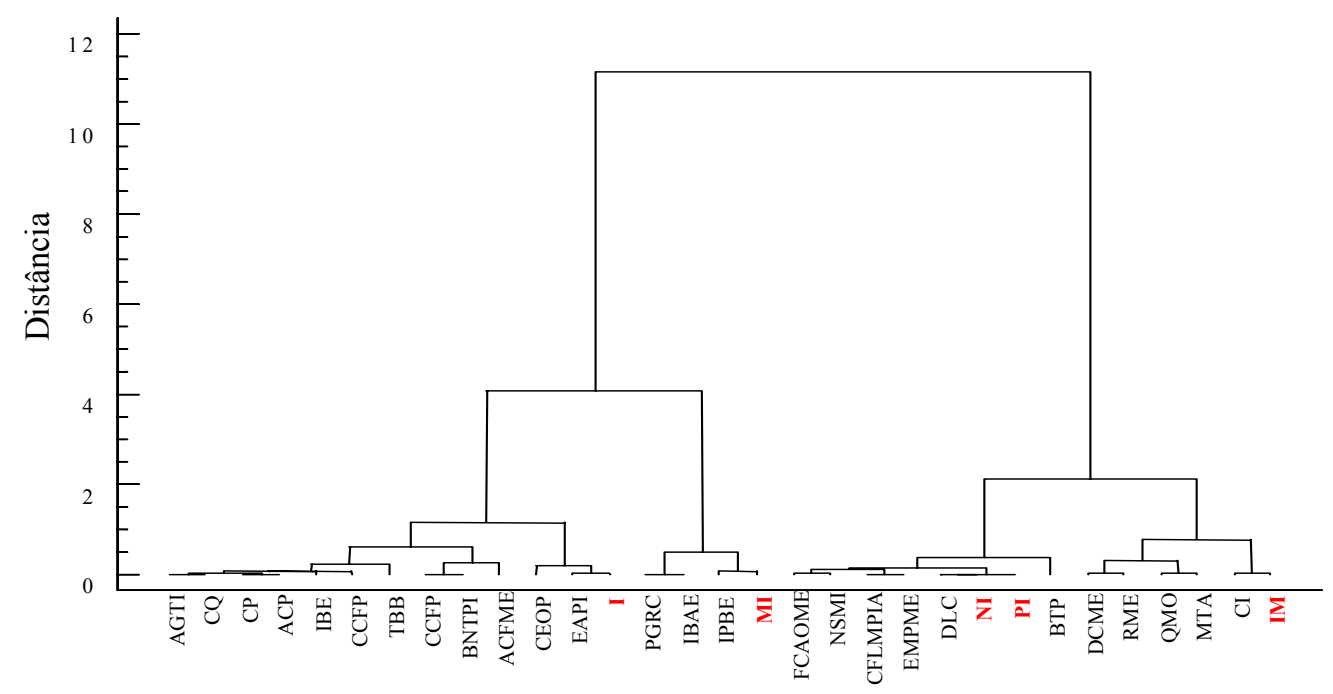

Figura 6. Dendrograma das barreiras e dos atributos de importância. (método de Ward).

Figure 6. Dendrogram of barriers and importance atributs (Ward's Method).

A metodologia empregada permite que os graus de importância para as barreiras sejam relativizados dentro de dois grupos principais. No primeiro grupo, formado por barreiras externas (ambiente de negócios nacional e internacional), as barreiras possuem também uma relação de importância relativa entre si. Assim, existem barreiras de maior importância (muito importante) e as de menor importância (importante). De igual modo, no segundo grupo, onde se concentram principalmente as barreiras internas, existem barreiras de maior importância (importância moderada) e de menor importância (não importantes e pouco importantes).

As barreiras mais importantes do primeiro grupo (Figura 6), ambiente externo, são portanto a imagem dos móveis do Brasil no exterior (IPBE), os impostos brasileiros afetando as exportações (IBAE) e a política cambial brasileira (PGRC).

A opinião de Domingos S. Rigoni, presidente da Abimóvel, ilustra a percepção do empresariado sobre a imagem dos móveis no exterior: "Um dos grandes problemas do Brasil é a ausência de uma marca forte, que seja conhecida no exterior. O resultado é que muitas vezes, quando participamos de feiras internacionais, os importadores deixam de se interessar pelos nossos produtos pelo simples fato de serem fabricados no Brasil (SASAKI, 2003)". Em 2003, a Abimóvel lançou um selo de qualidade para móveis, com o objetivo de incentivar as exportações por meio da melhoria da imagem do móvel brasileiro no exterior.

Os impostos brasileiros que afetam as exportações já foram apontados em outras pesquisas como sendo uma variável de grande importância para os empresários. Os empresários brasileiros elegeram, em Martins et al., a CPMF como sendo o imposto que mais afeta a competitividade das empresas nas exportações de móveis. Isso deve-se principalmente ao fato de esse imposto não possuir mecanismos de ressarcimento, como é o caso do PIS/Cofins e do ICMS. No caso destes últimos, o maior problema seriam as dificuldades no ressarcimento de créditos tributários.

Os resultados sobre a política cambial conferem com a literatura, segundo a qual esta variável é freqüentemente percebida como uma importante barreira para as exportações. Curiosamente, pouco mais de dois anos depois da realização desta pesquisa, surgiu um artigo com o seguinte título no jornal eletrônico Emobile: "Balanço da Abimóvel aponta: queda do dólar não impede crescimento das vendas externas" (EMOBILE, 2005). O artigo refere-se às sucessivas baixas cambiais entre 2004 e 2005. Esse fato demonstra que as alterações do câmbio podem até certo ponto ser absorvidas pela indústria. De qualquer modo, supõe-se que na Alca o Brasil tenha regras estáveis de comércio exterior, com taxas de câmbio equilibradas (ARAÚJO, 1998), fato que seria naturalmente favorável para a performance das exportações.

As demais barreiras externas analisadas enquadram-se em um subgrupo cujo atributo de importância característico é "importante". Nesse grupo, estão incluídos os fatores inerentes aos custos para exportar ou para iniciar a atividade exportadora: a) Altos custos de frete para o mercado externo (ACFME); b) Custos portuários (CP); c) Custo de capital para financiar as exportações (CCFE); d) Custo do capital para financiar a produção (CCFP). Os resultados estão em consonância com o estudo de Kume 
et al., no qual foram identificadas as despesas com seguro e frete e gastos com aduana como barreiras importantes para os empresários negociando no Mercosul.

Ainda dentro do segundo subgrupo de barreiras externas, enquadram-se barreiras relacionadas ao ambiente de negócios nacional, ou seja, trâmites burocráticos, altos custos de produção e assistência governamental e taxas de incentivo. O fato de a variável altos custos de administração ser incluída nesse grupo denota que os empresários atribuem esses altos custos a fatores relacionados às condições nacionais e não à capacidade gerencial das empresas.

As demais barreiras referem-se, principalmente, ao ambiente de negócios internacional, e o posicionamento delas no subgrupo de barreiras importantes parece estar de acordo com os resultados da literatura. No entanto, especial menção merecem as barreiras não-tarifárias. No contexto geral, essa barreira assume um grau de importância relativamente alto na presente pesquisa, ao passo que em Silva; Rocha (2001) e em Kume et al. (2001) os empresários que exportam para o Mercosul atribuem pequena importância para a referida barreira.

No segundo grupo de barreiras (Figura 6), formado preponderantemente por barreiras internas às empresas, observa-se primeiramente um subgrupo com maior importância (Importância Moderada). Nesse subgrupo, incluem-se barreiras ligadas preponderantemente à capacidade administrativa para atuar no mercado externo: a) Dificuldades de contatos no mercado externo; b) Percepção de riscos no mercado externo; c) Qualificação da mão-de-obra; d) Melhores técnicas administrativas; e) Conflitos com importadores.

No último subgrupo, enquadram-se as barreiras de menor importância para os empresários (não importante e pouco importante), incluindo tanto barreiras internas como externas. Dentre as barreiras internas, enquadram-se aquelas relacionadas principalmente com a capacidade produtiva das empresas: barreiras técnicas na produção, necessidade de servir o mercado interno e falta de capacidade para aumentar a oferta no mercado externo. É interessante notar que também é incluída nesse grupo a barreira externa exigências de modificação do produto no mercado externo, variável que também está relacionada à capacidade produtiva das empresas. Enfim, nesse subgrupo enquadra-se ainda uma barreira relacionada à capacidade administrativa das empresas, as diferenças de língua e cultura, e outra barreira relacionada ao ambiente externo, a concorrência de firmas locais no mercado da Alca.

\section{CONCLUSÕES}

Os resultados da pesquisa sobre a percepção geral dos empresários sobre a Alca indicam que não há um envolvimento suficiente para as negociações do acordo. Eles ainda não estão planejando em função do acordo e poucos participam de algum grupo de pressão para conseguir melhores condições de competitividade. Em contraste, os empresários julgam-se preparados para competir na Alca. Assim, esses resultados indicam que as respostas relativas às barreiras não teriam sido pensadas para a Alca, mas como barreiras para exportações de forma genérica.

No contexto geral das barreiras, evidenciou-se que os empresários atribuem alta importância às barreiras relativas ao ambiente de negócios externo às empresas. Esses resultados já foram constatados em outros estudos da literatura. No entanto, sugere-se, neste artigo, que esse fenômeno não seja tomado deterministicamente. É possível relativizar os resultados de modo a analisar o papel das barreiras internas e externas separadamente, sem que a relação de importância entre as variáveis desses grupos seja perdida.

Em um primeiro subgrupo, enquadram-se as barreiras externas de elevada importância. Elas incluem a imagem dos móveis brasileiros no exterior, as taxas de câmbio e os impostos brasileiros que afetam as exportações. Esses resultados são coerentes com os resultados da literatura sobre barreiras.

No segundo grupo de barreiras, foram ordenadas preponderantemente barreiras internas às empresas. No subgrupo das variáveis de maior importância, enquadram-se barreiras ligadas à capacidade administrativa para atuar no mercado externo. Por outro lado, no segundo subgrupo enquadram-se barreiras internas e algumas externas às firmas, mas sobretudo ligadas à atividade produtiva. Ou seja, se atribui maior importância para as barreiras gerenciais do que às produtivas das empresas. Isso significa que as firmas julgam-se capazes para competir internacionalmente pelo lado da produção, mas lhes faltam ainda melhores técnicas administrativas para alcançar melhores performances.

Metodologicamente, a análise fatorial de correspondências demonstrou possuir grande flexibilidade em seu uso. A principal vantagem da técnica para o caso de estudos envolvendo classificações é que a análise dos dados pode ser feita com base direta nos atributos perguntados na pesquisa (não importante, importante etc.). A utilização da análise de cluster como técnica complementar demonstrou-se também bastante útil para a interpretação dos resultados. A combinação das duas técnicas demonstrou que os resultados podem ser interpretados de maneira coerente. 


\section{REFERÊNCIAS}

AGÊNCIA DE PROMOÇÃO DE EXPORTAÇÕES (APEX). O comércio exterior brasileiro. Brasília, DF, 2002. Folder oficial.

ARAÚJO, J. T. de. Alca, riscos e oportunidades para o Brasil. In: SEMINÁRIO ALCA E MERCOSUL: riscos e oportunidades para o Brasil, 1998, Rio de Janeiro. Artigo02.doc. Disponível em: $<$ http://www2.mre.gov.br/ipri/salca.html >. Acesso em: 12/01/2003.

ASSOCIAÇÃO BRASILEIRA DAS INDÚSTRIAS DO MOBILIÁRIO (ABIMOVEL). PROMOVEL. Disponível em: $<\mathrm{http}: / /$ www.abimovel.org.br/> . Acesso em: 12/01/2003.

AT KEARNEY. 5179. ppt. Disponível em: <http://www.amcham.com.br/> Acesso em: 03/01/2002

AXINN, C. N. Export performance: do managerial perception make a difference? International Marketing Review, Bradford, v. 5, n. 5, p. 67-71, 1988.

BAUERSCHMIDT, A.; SULLIVAN, D.; GILLESPIE, K. Common factors underlying barriers to export: studies in the U.S. paper industry. Journal of International Business Studies, Columbia, SC, p. 111123, Fall, 1985.

BENDIXEN, M. A practical guide to the use of correspondece analysis in marketing research. Marketing Research On-Line, United States, v. 1, 1996. Disponível em: <www.periodicos.capes.br> Acesso em: 23/02/2003.

BRASIL. Ministério do Desenvolvimento, Indústria e Comércio Exterior (MDIC). Estudo da competitividade de cadeias integradas do Brasil. Disponível em: $<\mathrm{http}$ ://www.desenvolvimento.gov.br/cadeiasprodutivas/> Acesso em: 14/01/2003.

CARRIER, C. "Les besoins de formation et de perfectionnement des propriétaires-dirigeants de PME potentiellement exportatrices", In: CONGRÈS INTERNATIONAL FRANCOPHONE DE LA PME, 3. Trois-Rivières. Actes du... Québec: Université, 1996. p. 322-337.

CARVAlHO, A.; PARENTE, A. Impactos comerciais da Área de Livre Comércio das Américas. Brasília: IPEA. 1999. (Textos para discussão, n. 635).

CHRISTENSEN, C.; ROCHA, A. da; GERTNER, R. K. An empirical investigation of factors influencing exporting success of Brazilian firms, The Journal of International Business Studies, United Kingdom, v. 18 , n. 3, p. 61-77, 1994.

CONFEDERAÇÃO NACIONAL DAS INDÚSTRIAS (CNI) Os problemas da empresa exportadora brasileira. Brasilia, 2002.

CUNHA JÚNIOR, M. V. M. Análise multidimensional de dados categóricos: aplicação das análises de correspondência em marketing e sua integração com técnicas de análise de dados quantitativos Revista de Administração, [S.;1.], v. 35, n.. 1, p. 32-50, jan./mar., 2000.

DEAN, D. L.; MNEGÜÇ, B.; MYERS, C. P. Revisiting Firm Characteristics, Strategy, and Export Performance Relationship: A survey of the Literature and an Investigation of New Zealand Small Manufacturing Firms. Industrial Marketing Management, New York, n. 29, p. 461-477, 2000.

DOMINGUES, E. P.; HADDAD, E. A.; Perspectivas da implementação da Alca na economia brasileira: impactos setoriais e regionais da abertura comercial. Belo Horizonte: UFMG/Cedeplar, 2003. 24 p. (Texto para discussão, n. 208).

EMOBILE. Exportações crescem: balanço da Abimóvel aponta queda do dólar não impede crescimento das vendas externas. 2002 Disponível em:

$<$ http://www.emobile.com.br/noticias.asp?pidInformacao=5657>. Acesso em: 20/05/2005.

GOURGEL, A. C.; BITENCOURT, M. B.; TEIXEIRA, E. C. Impactos de liberalização comercial Alca e o Mercoeuro sobre os países membros. Revista Brasileira de Economia, Rio de Janeiro. v. 56, n. 2, p. 335-369, 2002. 
HAIR, J. F.; ANDERSON, R. E. E.; TATHAM, R. L.; BLACK, W. C. Multivariate data analysis: with readings. 4 ed. Upper Saddle River, New Jersey: Prentice-Hall, 1995.

HOFFMAN, D.; FRANKE, G. Correspondence analysis: graphical representation of categorical data in marketing research. Journal of Marketing Research,Chicago, v. 23, p. 213-227, Aug., 1986.

INFANTE, V. S.; IDROGO, A. A. As atividades de marketing utilizadas pelo exportador do Estado do Rio Grande do Norte Revista de Administração, [S.;1.], v. 23, n. 2, p. 29-43, 1988.

JOHNSON, R. A.; WICHERN, D. W. Applied multivariate statistical analysis. New Jersey: Prentice Hall, 1998.

KACIAK, E.; LOUVIERE, J. Multiple correspondence analysis of multiple choice experiment data. Journal of Marketing Research., Chicago, v. 27, p. 455-65, Nov., 1990.

KARAKAYA, F.; HARCAR, T. Barriers to export for non-exporting firms in developing countries. Academy of Marketing Studies Journal, United States, v. 3, n. 2, p. 59-77, 1999.

KATSIKEAS, C. S.; MORGAN, R. E. Differences in perceptions of exporting problems based of firm size and export market experience. European Journal of Marketing, Bradford, v. 28, n. 5, p. 17-35, 1994.

KAYNAK, E. A cross regional comparison of export performance of firms in two Canadian regions. MIR. Management International Review, Wiesbaden, v. 32, n. 2, 1992.

KORTH, C. M. Managerial barriers to U.S. exports. Business Horizons, Bloomington, v. 28 , p.18 26, 1985.

KUME, H.; ANDERSON, P.; OLIVEIRA JR., M. Identificação das barreiras ao comércio no Mercosul: a percepção das empresas exportadoras brasileiras. Rio de Janeiro: IPEA, 2001. 48 p. (Texto para discussão, n. 789).

LEONIDOU, L. Export barriers: non-exporters' perceptions. International Marketing Review, Bradford, v. 12, n. ${ }^{\circ}$ 1, p. 4-25, 1995.

MARTINS, G.; FRANZONI, A. J.; SILVA, J. C. L. da. Indústria brasileira de móveis: problemas enfrentados nas atividades de exportação. Revista Univille, Joinville, v.9, n. 1, p. 73 - 85, 2004.

MARTINS, G.; Percepção dos empresários sul-brasileiros do setor de móveis com relação à Alca. 130 f. Dissertação (Mestrado em Ciências Florestais) - Setor de Ciências Agrárias, Universidade Federal do Paraná, Curitiba, 2003. 130p Disponível em: <www.ipef.br>

PARRA, J. F. R. Um modelo conceitual para a alavancagem da competitividade internacional das empresas industriais. 406 p. Tese (Doutorado em Administração) - Escola de Administração de Empresas de São Paulo, Fundação Getúlio Vargas, São Paulo, 1996.

SASAKI, D. Móveis terão selo de garantia ano que vem. Gazeta Mercantil, Curitiba, 20 fev. 2003. Região Sul, certificação, ano VI, n. ${ }^{\circ} 1.388$, p. 3.

SILVA, J. C. G. L. A. da. Análise da formulação de estratégias de marketing internacional de empresas de papel e celulose.. 247 p. Tese (Doutorado em economia aplicada) - Escola Superior de Agricultura Luiz de Queiroz, Universidade de São Paulo, Piracicaba, 1996.

SILVA, P. A. da; ROCHA, A. da. Perception of export barriers to Mercosur by Brazilian firms. International Marketing Review, Bradford, v. 18, n. 6, p. 589 - 610, 2001.

ROCHA, A.; CHRISTENSEN, C. H. The export experience of a developing country: a review of empirical studies of export behavior and the performance of Brazilian firms. Advances in International Marketing, United States, v. 6, p.111-142, 1994.

UNIVERSIDADE ESTADUAL DE CAMPINAS. Instituto de Economia. Núcleo de Economia Industrial e da Tecnologia (UNICAMP- IE-NEIT). Estudo da competitividade de cadeias integradas no Brasil: impactos das zonas de livre comércio: cadeia: madeira e móveis. Campinas, 2002. 212 p. Relatório técnico.

VALENTIN, J. L. Ecologia numérica. Rio de Janeiro: Interciência, 2000. 